\title{
Identidade cultural no consumo de fãs brasileiros da National Football League
}

\author{
BRUNO MELO MOURA ${ }^{1}$ \\ ANdrÉ LUIZ MARANHÃo de SOUZA-LEÃo ${ }^{1}$ \\ ${ }^{1}$ Universidade federal de Pernambuco (UfPe) / Programa de Pós-Graduação em Administração, Recife - PE, Brasil
}

\begin{abstract}
Resumo
Os telespectadores brasileiros da NFL interagem nas mídias sociais durante a transmissão dos jogos da liga. Uma vez que as práticas de consumo de fãs podem estabelecer identidades pela intensidade do envolvimento com os produtos de mídia, a presente pesquisa visa analisar como os fãs brasileiros da NFL constituem identidades culturais em suas interações em mídia social durante a transmissão dos jogos da liga. Para tanto, utilizamos a netnografia, método que é comumente utilizado em estudos que buscam compreender fenômenos culturais que ocorrem por meio de interações online. O corpus da pesquisa foi formado por mensagens postadas por fãs nas hashtags do Twitter criadas pelos canais ESPN do Brasil, durante os jogos veiculados no decorrer das temporadas 2016-2017 e 2017-2018. Os resultados indicam a constituição de três categorias identitárias: nacionalismo, como forma de projetar uma imagem idealizada de nação; localismo, como demarcação das tensões das diferenças existentes no país; e minorias sociais relacionadas a gênero e orientação sexual, revelando tensões e conformidades na construção social dessas posições. Ao revelar identidades fortemente relacionadas à noção de lugar e a representações diferentes da hétero-masculina, tais achados são evidenciados como uma versão particular dos valores centrais do próprio esporte em seu país de origem.
\end{abstract}

Palavras-chave: NFL. Identidade cultural. Fãs. Prossumo. Netnografia.

\section{Cultural identity in the consumption of the National Football League by Brazilian fans}

\begin{abstract}
Brazilians watching the US National Football League (NFL) interact on social media during the broadcast of league games. Since fan consumption practices can establish identities from the intensity of involvement with media products, this research aims to analyze how Brazilian NFL fans constitute cultural identities in their interactions on social media during the broadcast of league games. We use netnography, a method commonly used in studies that seek to understand cultural phenomena that occur through online interactions. The research corpus was formed by messages posted by fans on Twitter hashtags created by the ESPN channels of Brazil, during the games broadcasted in the 20162017 and 2017-2018 seasons. The results indicate three identity categories: nationalism, as a way of projecting an idealized image of a nation; localism, as a demarcation of tensions of the differences existing in the country; and social minorities related to gender and sexual orientation, revealing tensions and conformities in the social construction of these positions. By revealing identities strongly related to the notion of place and different representations of the hetero-masculine, these findings are evidenced as a particular version of the central values of the sport itself in its country of origin.
\end{abstract}

Keywords: NFL. Cultural identity. Fans. Prosumption. Netnography.

\section{Identidad cultural en el consumo de fanes brasileños de la National Football League}

\section{Resumen}

Los espectadores brasileños de la NFL interactúan en las redes sociales durante la transmisión de los juegos de la liga. Dado que las prácticas de consumo de fanes pueden establecer identidades por la intensidad de la participación en los productos de los medios, la investigación actual se propone analizar cómo los fanes brasileños de la NFL constituyen identidades culturales en sus interacciones en las redes sociales durante la transmisión de los juegos de la liga. Para tal fin, utilizamos la netnografía, un método que se usa comúnmente en estudios que buscan comprender los fenómenos culturales que ocurren a través de las interacciones en línea. El corpus de investigación se compuso por mensajes publicados por los fanes en etiquetas de Twitter creadas por los canales de ESPN de Brasil, durante los juegos transmitidos durante las temporadas 2016-2017 y 2017-2018. Los resultados indican la constitución de tres categorías de identidad: el nacionalismo, como una forma de proyectar una imagen idealizada de una nación; el localismo, como demarcación de las tensiones de las diferencias existentes en el país; y las minorías sociales relacionadas con el género y la orientación sexual, revelando tensiones y conformidades en la construcción social de estas posiciones. Al revelar identidades fuertemente relacionadas con la noción de lugar y con representaciones diferentes de la heteromasculina, tales hallazgos se evidencian como una versión particular de los valores centrales del deporte en su país de origen.

Palabras clave: NFL. Identidad cultural. Fanes. Prosumo. Netnografía. 


\section{INTRODUÇÃO}

A sociedade moderna pode ser entendida por meio de suas manifestações culturais de entretenimento, sendo o esporte uma de suas principais fontes (RUDDOCK, 2010; WHANNEL, 2014). O esporte pode denotar eventos sociais, representar aspectos locais e disseminar detalhes das culturas às quais faz parte (WENNER, 2012; WHANNEL, 2014). É o caso do futebol americano em relação aos Estados Unidos da América (EUA). O esporte se tornou o mais popular do país (ORIARD, 2007) e sua principal liga, a National Football League (NFL), tem intensificado seu crescimento em todo o mundo (SEIFERT, 2017).

Como marca, a NFL possui grande valor econômico, sendo a liga mais lucrativa do mundo (OZANIAN, 2017). Além disso, tem grande importância social e cultural, já que possui a capacidade de direcionar percepções sociais e moldar práticas da tradição (WENNER, 2012, 2014; WHANNEL, 2014), além de contar com fãs altamente engajados que atuam como propagadores da liga (OATES e FURNESS, 2014).

A maneira de consumir o futebol americano tem mudado junto com sua principal liga. A NFL não mais prioriza os fãs que assistem aos jogos nos estádios, mas aqueles que acompanham as transmissões televisivas (WENNER, 2014). Ela adere à forma moderna de difundir e consumir esportes, segundo Whannel (2014): esportes de mídia são transmitidos por grandes conglomerados midiáticos e impactados por sua audiência; esportes de prática são populares por seu grande número de praticantes. A relação entre os dois tipos é dinâmica: as sociedades podem desenvolver interesse por esportes de mídia a partir de sua prática e os esportes de prática podem ganhar adeptos devido à sua difusão na mídia.

Esportes de mídia são considerados fenômenos globais pela relevância que suas transmissões alcançam. Eles não são limitados por fronteiras geográficas, no entanto, alguns deles, mesmo que transmitidos em vários mercados do mundo, não podem ser considerados globais. Isso acontece quando suas práticas e regras são estranhas à maioria dos indivíduos de uma cultura local (RUDDOCK, 2010; WHANNEL, 2014). É o caso do futebol americano e da NFL que, apesar de seu crescimento contínuo em todo o mundo, ainda não pode ser considerado global. Na maior parte do mundo o esporte não possui um público majoritário, sendo considerado alternativo e exótico quando comparado a outros esportes, assim como sua prática é incipiente (SEIFERT, 2017).

Isso acontece no Brasil, onde o esporte ainda não é completamente familiar. Contudo, o país possui um dos maiores públicos da NFL no mundo (ESPN BRASIL, 2015, MAGRI, 2018), alcançando uma grande audiência (ESPN BRASIL, 2017). O Brasil é o segundo maior mercado internacional da NFL, com quase 20 milhões de espectadores, atrás apenas do México, que faz fronteira com os EUA e é sede de jogos da liga desde 2005 (ESPN BRASIL, 2015).

A transmissão brasileira da NFL também conta com um envolvimento significativo dos fãs por meio das mídias sociais (ESPN BRASIL, 2017). Os espectadores brasileiros da NFL interagem em redes sociais durante a transmissão dos jogos da liga. Isso ocorre em hashtags do Twitter criadas pelos canais brasileiros da ESPN para comunicação entre fãs e entre eles e a própria emissora de televisão (MAGRI, 2018).

As mensagens publicadas na plataforma digital podem ser caracterizadas como uma prática proativa do consumidor, pois, ao optar por discutir os jogos entre eles, o espectador não se restringe ao ato de consumir passivamente um produto de entretenimento. Nesse sentido, os fãs são consumidores produtivos, por meio da apropriação de textos midiáticos, negociando seu significado e difundindo seu conteúdo, o que pode ser considerado um exercício de resistência ao modelo de recepção de consumo passivo (JENKINS, 2008). Portanto, do ponto de vista da Consumer Culture Theory (CCT), os fãs se assemelham ao conceito de prossumidores (LEÃO e COSTA, 2018), já que assumem tarefas que, geralmente, pertencem aos produtores, de acordo com o modelo dualista de produção e consumo (RITZER, 2015; RITZER e JUNGERSON, 2010).

Esse envolvimento indica uma grande identificação dos fãs com o que consomem. Como o consumo é uma prática cultural do mundo contemporâneo, permite ao consumidor estabelecer identidades por meio de recursos sociais e simbólicos que são fornecidos e/ou legitimados por práticas de mercado (ARNOULD e THOMPSON, 2005; BELK e CASOTTI, 2014). Dessa forma, as práticas de consumo de fãs podem estabelecer identidades pela intensidade do envolvimento intelectual e emocional com produtos de mídia (GUSCHWAN, 2012).

Esses aspectos nos levam a entender que a interação dos telespectadores brasileiros da NFL, quando observada como prática de consumo, indica formações identitárias. Em consonância com isso, em uma recente revisão das reverberações teóricas da CCT, Arnould e Thompson (2015) argumentam que esse tipo de consumo faz parte de um subsistema de redes fragmentadas interconectadas que fornecem recursos para o trabalho de identidade dos consumidores. 
Seguindo Hall $(2012,2013,2014)$, assumimos que esse trabalho identitário é cultural, se referindo a posições constituídas por relações socioculturais que são incorporadas pelos indivíduos em sua própria elaboração identitária. Essa noção de identidade cultural foi elaborada no campo dos Estudos Culturais como forma de conceber o sujeito pós-moderno como uma construção fragmentada, capaz de aderir a diferentes identidades culturalmente constituídas, de acordo com os diferentes campos sociais em que se opera (WOODWARD, 2012).

A partir do entendimento de que práticas de consumo são capazes de constituir identidades culturais, a presente pesquisa tem como objetivo analisar como os fãs brasileiros da NFL constituem identidades culturais em suas interações nas mídias sociais durante a transmissão dos jogos da liga.

A pesquisa explora duas camadas de contribuição para os estudos da CCT: a formação de identidade através do consumo de um esporte de mídia estrangeiro por um público local e o foco nesse fenômeno por meio de interações em redes sociais. Apesar da narrativa de identidade ser um tópico de investigação já estabelecido no campo da CCT (ver ARNOULD e THOMPSON, 2005, 2015), existe uma carência de estudos sobre isto em relação a comunidades virtuais de consumo como os fandoms. Seguimos Kozinets (2015) no entendimento de que as redes sociais são espaços sociais tão complexos quanto outras esferas da vida social. Esta concepção se alinha, assim, às noções dos Estudos Culturais acerca da cultura desterritorializada, que desprende a concepção de cultura de seu vínculo espacial (APPADURAI, 1996; HALL, 2014), e de espaços de fluxos, que são arranjos - tais como ambientes online -, configurados para permitir que práticas sociais ocorram fora de territórios físicos (CASTELLS, 2011).

\section{Fãs como Consumidores Produtivos}

Os fãs podem ser entendidos como consumidores singulares: por um lado, são caracterizados pela intensidade de envolvimento intelectual e emocional que possuem com os produtos que admiram; por outro, são entendidos como capazes de recriar o texto midiático que recepcionam (GUSCHWAN, 2012; LANIER e RADIER; FOWLER III, 2015). Portanto, os fãs são comumente definidos pelas atividades que realizam (DUFFET, 2013).

A participação ativa do consumidor na ressignificação de produtos ou mesmo na produção de novos conteúdos baseados neles por meio da apropriação tecnológica é caracterizada como um fenômeno conhecido como cultura participativa (JENKINS, 2006). Isso acontece devido à convergência dos consumidores. Eles se envolvem em práticas coletivas de interação, se tornando membros ativos das comunidades (LANGLOIS, 2013; JENKINS, 2006).

Geralmente, os fãs se organizam em fandoms (COSTA e LEÃO, 2018). São comunidades onde interagem, desenvolvem, compartilham e divulgam suas experiências e práticas de consumo (GUSCHWAN, 2012; JENKINS, FORD e GREEN, 2010). Além disso, trata-se de um arranjo social que está se tornando cada vez mais comum, graças à crescente indústria do entretenimento e aos avanços tecnológicos (HEWER, GANNON e CORDINA, 2015; JENKINS, 2006). Portanto, fandoms são comunidades de consumidores cujos membros se relacionam virtualmente por meio de interesses comuns, mesmo que pertençam a diferentes mundos culturais (KOZINETS, 2006).

Comunidades de consumidores são instâncias que podem possibilitar a constituição e manutenção de identidades (LUEDICKE, THOMPSON e GIESLER, 2010). Quando os consumidores se reúnem em tribos comunitárias e comunidades de marca, interagem ativamente sobre o assunto que os une (BHATTACHARJEE, BERGER e MENON, 2014; COVA, PACE e SKÅLÉN, 2015). As comunidades de consumidores atuam nas identidades dos consumidores em virtude de as práticas coletivas de consumo constituírem e exaltarem comportamentos e escolhas individuais (LUEDICKE, THOMPSON e GIESLER, 2010; THOMAS, PRICE e SCHAU, 2013). Elas podem ser interpretadas como comunidades imaginadas (ANDERSON, 1987), um senso de comunhão que gera uma identidade coletiva formada por uma pluralidade de identidades.

Assim, é relevante explorar como os fandoms podem contribuir para o trabalho de identidade. Essa prática se torna possível porque os fãs mostram uma nova maneira de exercitar identidades relacionadas às práticas de consumo, principalmente por meio de atos de colaboração e cidadania (GUSCHWAN, 2012; JENKINS, 2008). Como os fãs são naturalmente buscadores de conteúdo, eles usam o fandom para articular suas posições políticas e senso de moralidade (JENKINS, 2013). Os fandoms levam a um senso de identidade comunitária, alinhado aos produtos de mídia que consomem, mas também são capazes de resistir e contestá-los (FILLIS e MACKAY, 2014; HEWER, GANNON e CORDINA, 2015). 


\section{Identidades de Consumo}

As práticas modernas de consumo permitem que as pessoas vislumbrem uma ideia empreendedora de si mesmas. Nesses atos, é possível formular e expressar identidades, na medida em que um indivíduo se comporta de acordo com o grupo, comunidade, rede ou ambiente ao qual está conectado (BHATTACHARJEE, BERGER e MENON, 2014). Isso é facilitado pela infinidade de recursos disponíveis para as práticas do consumidor, propícios à construção da identidade. O consumo, portanto, desempenha um papel importante na formulação da identidade, pois carrega significados simbólicos. Essas representações significativas definem os grupos aos quais os consumidores individuais pertencem e estabelecem a relação entre identidade e consumo de maneira social e simbólica (BARTIKOWSKI e WALSH, 2015; BELK, 2014).

Logo, as práticas de consumo têm capacidade etnocêntrica de legitimar a formação de identidades. Elas funcionam como uma estrutura material e simbólica na qual os indivíduos constroem identidades com base nas culturas das quais participa (ZEUGNERROTH, ZABKAR e DIAMANTOPOULOS, 2015). Esse etnocentrismo do consumo os legitima para a formação de identidades em meio à cultura em que se faz parte, uma vez que suas práticas podem revelar a existência de uma estrutura social que é material e simbólica (ARNOULD e THOMPSON, 2015; COVA e COVA, 2014). Tais identidades permitem que os consumidores apresentem diferentes facetas de si mesmos, variando de acordo com o tempo, cultura e contexto social (BELK, 2014).

Embora perceptíveis no nível individual, as identidades dos consumidores são elaboradas a partir das coletividades. Assim, as identidades são compartilhadas por indivíduos que acreditam ter interesses comuns, tanto que se reúnem para interagir sobre eles (ARVIDSSON e CALIANDRO, 2015). Identidades coletivas geralmente emergem por meio da interação social. Da mesma forma, os consumidores se agrupam em comunidades que lhes permitem coexistir virtualmente, mesmo que pertençam a diferentes mundos culturais (COVA e PACE, 2006; THOMAS, PRICE e SCHAU, 2013). Desta forma, identidades de consumo podem ser entendidas como resultantes de um trabalho articulado em meio a subsistemas de consumo fragmentados (ARNOULD e THOMPSON, 2015; COVA e COVA, 2014).

É por meio do consumo que os fãs estabelecem suas práticas. Eles se relacionam com os produtos que consomem pela intensidade do envolvimento intelectual e emocional com a mídia, capaz de gerar um compromisso com esta (GUSCHWAN, 2012). A identificação de fãs geralmente ocorre em fandoms (HEWER, GANNON e CORDINA, 2015), a partir dos quais é possível interpretar as estruturas da cultura de fãs como uma indicação de uma nova maneira de se pensar sobre colaboração, assim como na construção e exercício de identidades (GUSCHWAN, 2012; JENKINS, 2008). Essa concepção assume o consumo cultural como uma rede distribuída e fluida, na qual seus participantes são alinhados por processos recíprocos, auto organizados e constantemente reconfigurados (ARNOULD e THOMPSON, 2015).

\section{Identidades Culturais}

A teoria da identidade adotada neste estudo tem por base a conceituação desenvolvida no campo dos Estudos Culturais, especialmente por Stuart Hall. Hall $(2012,2013,2014)$ define identidade cultural como uma posição caracterizada por uma gama de significados inerentes a um sistema cultural e constituída graças ao compartilhamento de códigos e sinais mútuos. Trata-se de uma posição social resultante de uma dialética entre o indivíduo e a sociedade em que está inserido. Os processos sociais moldam, conservam ou reformulam identidades culturais, e a noção de identidade que o indivíduo adota influencia a escolha pelas estruturas e processos sociais de que participar.

Esse processo dialético faz com que as identidades culturais sejam marcadas pela diferença, sendo singular e mutuamente dependente. Logo, uma certa identidade existe apenas na medida em que outras também existem e são acessíveis a ela, em um processo de constituição por afirmação e negação (HALL, 2013). Enquanto a abordagem clássica da identidade apontava para um conceito de unidade, a perspectiva contemporânea indica multiplicidade, fluidez e fragmentação. É a noção de diferença que concebe a identidade cultural a partir do vínculo entre o indivíduo e as culturas com as quais ele se relaciona (HALL, 2012). Portanto, elas são relacionais; forjadas e mantidas em diferentes esferas da vida social e cultural (e.g., trabalho, linguagem, religião). Essa relação, no entanto, não ocorre simetricamente, uma vez que uma mesma identidade é capaz de articular aspectos diferentes da mesma cultura ou aspectos de culturas diferentes (HALL, 2012, 2014; SILVA, 2012).

Identidades culturais, portanto, resultam da dialética entre sociedade e indivíduo. Indivíduos sociais participam de sua constituição coletiva e então as incorporam em vez de pertencer a elas (HALL, 2014; WOODWARD, 2012). Isso acontece em 
um processo dinâmico e negociável no qual os indivíduos podem pertencer a várias posições de identidade simultaneamente. Logo, leva os indivíduos a se posicionarem na sociedade (BAUMANN e GINGRICH, 2005; MIGUELES e ZANINI, 2018). Assim, as identidades culturais são baseadas na alteridade, uma vez que uma identidade existe apenas em função de sua distinção de outra, bem como da identificação de indivíduos em relação a elas e entre eles mesmos (HALL, 2013, 2014).

As identidades culturais derivam de um processo de produção de significados que ocorre em meio a tensões e contradições, com base em descrições culturais. Isso permite que os atores sociais assumam identidades diferentes, devido aos diferentes campos nos quais se movem na vida social, ou à própria relação entre identidades diferentes (HALL, 2014; WOODWARD, 2012). Os indivíduos se tornam sujeitos fragmentados, capazes de negociar aspectos de diferentes culturas. A fragmentação das identidades leva o indivíduo a estar em um processo contínuo de transição, no qual aspectos culturais e sociais são negociados no seu cotidiano (BAUMANN e GINGRICH, 2005; TILIO, 2009).

Essas negociações contínuas mostram como as identidades pós-modernas são descentralizadas, fragmentadas e contraditórias, revelando o deslocamento das identificações individuais impulsionadas por diferentes direções dos sistemas de significado e representação cultural. Assim, existe uma multiplicidade de identidades possíveis às quais os indivíduos podem estar identificados simultânea e dinamicamente (HALL, 2014; OLIVEIRA e LEÃO, 2012). O construto se assemelha à noção pósmoderna de subjetividade, assumida como sendo formulada com base na prática social. Por outro lado, pode se argumentar que foi acentuado pelo processo de globalização (HALL, 2014). O mundo globalizado de hoje leva os sistemas sociais a um hibridismo cultural, resultante principalmente de uma variedade de identidades exercidas e sujeitas a sistemas culturais. Nesse contexto, a ampla adoção de novas tecnologias da informação e comunicação (TIC) torna as barreiras físicas (i.e., fronteiras, contato presencial) de diferentes culturas que influenciam a rotina das pessoas cada vez menos visíveis (BESSI, SCHREIBER, PUFFAL et al., 2015; CASTELLS, 1999).

Du Gay (1997) insere a questão da identidade cultural em um sistema mais amplo que a interconecta com representações sociais, regulação, produção e consumo. De forma alinhada a Hall (2013), o autor indica como a cultura deve ser entendida como um circuito, uma vez que possui importantes elementos presentes nos processos culturais, que vão da produção de artefatos culturais até as representações às quais estão associados. É possível produzir identidades a partir de representações, ou pela maneira como os artefatos culturais são consumidos e, ulteriormente, pelos mecanismos de poder que regulam sua produção e distribuição.

Leão e colegas (FRANCO e LEÃO, 2014; LEÃO, IANATONI e CAVALCANTI, 2015; LEÃO e MELLO, 2012; OLIVEIRA e LEÃO, 2012) articulam a identidade cultural como identidade de consumo, inscrevendo o consumo um como sistema cultural capaz de produzir e legitimar as identidades culturais. Quando os indivíduos interagem nas comunidades, demarcam diferenças e particularidades que revelam identidades distintas (WOODWARD, 2012) que podem ou não estar alinhadas com o conteúdo produzido pelas marcas (LEÃO, IANATONI e CAVALCANTI, 2015). Como salientam Franco e Leão (2014), o consumo fornece uma constituição e expressão de identidades culturais pela interação entre marcas e consumidores.

\section{PROCEDIMENTO METODOLÓGICOS}

A pesquisa não seguiu um delineamento verificacionista, baseado em construtos teóricos. Em vez disso, a teoria foi usada para fundamentar a concepção da pesquisa e, principalmente, como um meio de interpretar os resultados. Assim, não foi adotada na forma de categorias conceituais para a fundamentação do trabalho empírico (LEÃO, MELLO e VIEIRA, 2009), o que está de acordo com o paradigma da pesquisa interpretativista (LINCOLN, LYNHAM e GUBA, 2011).

A pesquisa foi realizada por meio de uma netnografia. O método é comumente utilizado em estudos que buscam entender fenômenos culturais que ocorrem por meio de interações online (BEGNINI, SANTOS, SEHNEM et al., 2019; IZOGO e JAYAWARDHENA, 2018). A rigor, a netnografia é uma adaptação do método etnográfico ao ambiente virtual. Foi desenvolvida para investigar o comportamento do consumidor em estudos de marketing, incorporando culturas e comunidades mediadas on-line (BARTL, KANNAN e STOCKINGER, 2016; HENRIQUES e PEREIRA, 2018).

A netnografia foi escolhida em virtude da principal comunidade de consumidores da NFL no Brasil ser mediada on-line em hashtags promovidas pelos canais ESPN. Essas hashtags são postadas no Twitter, uma das redes sociais mais famosas do mundo (VAN DJICK, 2013). Como aponta Kozinets $(2010,2015)$, o método é apropriado para investigar fóruns, blogs e redes 
sociais. Isso porque é capaz de capturar particularidades de interação social com base no uso de tecnologias que não são possíveis em etnografias desenvolvidas para fins antropológicos ou realizadas em locais físicos (HAMILTON e ALEXANDER, 2017; SCARABOTO e PEREIRA, 2013).

Nas comunidades virtuais, as identidades são construídas por meio da produção textual material (e.g., textos, fotos, vídeos, avatares) (CHERNEV, HAMILTON e GAL, 2011; KOZINETS, 2010). É assim que funcionam os encontros presenciais em ambientes on-line (LEÃO, IANATONI e CAMARGO, 2015). A maneira como os indivíduos se organizam em uma rede leva as conexões culturais a serem não apenas sociais e econômicas, mas fluidas, flexíveis e dinâmicas (CASTELLS, 1999). Culturas que antes não tinham contato agora são acessadas simultaneamente em um fenômeno de hibridação, estabelecido, geralmente, no domínio virtual (CANCLINI, 2006; LÉVY, 1999). Nesse contexto, as interações sociais são estabelecidas principalmente nas Comunicações Mediadas por Computador (CMC) (KOZINETS, 2015). Investigar esse tipo de fenômeno permite a compreensão de uma ampla variedade de efeitos culturais, incluindo comportamentos e práticas individuais e coletivas (BARTL, KANNAN e STOCKINGER, 2016), de uma maneira que só pode ser vista nos ambientes on-line (i.e., avatares, memes) e que depende da sincronicidade na qual os dados são coletados (KOZINETS, 2010). Portanto, dispositivos tecnológicos e o uso de redes sociais permitem que pesquisas qualitativas lidem com fenômenos que ocorrem em ambientes on-line (IACONO, SYMONDS e BROWN, 2016).

Para orientar nossa pesquisa, foi adotada a abordagem proposta por Kozinets (2006, 2010, 2015). Ela tem sido amplamente adotada em estudos de marketing e principalmente na pesquisa do consumidor. O método é proposto em três etapas, descritos a seguir.

Entrée Cultural. Um processo no qual os pesquisadores se naturalizam com a cultura a ser investigada, a fim de perceber detalhes que apenas membros da comunidade são capazes. Para nossa pesquisa, optamos por observar as interações entre os fãs brasileiros da NFL por meio da troca de mensagens no Twitter. Eles são estimulados pelos canais ESPN durante as transmissões locais dos jogos da liga. A emissora foi o primeiro canal de TV paga a transmitir os jogos da NFL no Brasil, em setembro de 1992, detendo direitos exclusivos da liga no país desde 2017 (FIRMINO, 2018; FRANCISCHINI, 2018). Essa etapa ocorreu naturalmente, pois os dois pesquisadores são telespectadores da NFL desde 2009. Um deles é membro ativo da comunidade investigada desde 2011, mesmo período em que também é jogador da liga brasileira de futebol americano.

Coleta de dados. Procedimento que consiste em arquivar as interações on-line observadas. A coleta de dados funciona com base no arquivamento tanto do texto da interação mediada na comunidade on-line, como de outros conteúdos que fazem parte das interações observadas (i.e., fotos, vídeos). É um processo que geralmente é feito em momentos diferentes, seja porque a análise e interpretação dos dados podem exigir a coleta de novos dados, seja para se obter o nível de saturação. Esta etapa também pode ser complementada por notas de campo. No período de nossa investigação, a comunidade interagiu principalmente durante as transmissões do jogo. Foram monitoradas quatro hashtags lançadas pela ESPN brasileira, cujos tweets foram salvos e arquivados: \#TudoPelaNFL, \#PlayOffsNFLnaESPN e \#SuperBowlnaESPN (temporada 2016-2017) e \#NFLnaESPN (temporada 2017-2018). Ainda, foram gravados os jogos transmitidos pela ESPN brasileira (119 na primeira temporada e 141 na segunda), a fim de servir como um contexto imediato para a análise dos comentários dos fãs.

Análise de dados. A última etapa pode ser dividida em passos de procedimentos analíticos: codificação, reflexão, abstração, comparação, verificação, refinamento, generalização teórica e (uma possível) teorização. Organizamos esses passos em três momentos de análise. Primeiro, realizamos uma rodada de análise para estabelecer códigos provisórios, além de classificar e hierarquizar os dados coletados. Em seguida, filtramos os dados para gerar identificações e relações mais claras que foram reveladas como categorias mais amplas. Finalmente, interpretamos essas categorias à luz da literatura. No entanto, essa análise teve um caráter indutivo na primeira temporada, uma vez que a literatura serviu como lentes analíticas em vez de categorias a priori. Durante a segunda temporada, ocorreu uma abordagem parcialmente dedutiva, pois partimos das categorias inferidas no primeiro período, mantendo, no entanto, o processo aberto à identificação de novos códigos e categorias.

Para atender aos critérios de qualidade da pesquisa qualitativa, adotamos os critérios para uma netnografia indicados por Kozinets (2015), que dão conta da saturação dos dados, argumentos axiológicos estabelecidos no entrée cultural, reflexividade dos pesquisadores e respeito à práxis observada. Além disso, questões éticas foram consideradas, seguindo direcionamentos de Kozinets (2006). Não causamos danos à comunidade analisada, uma vez que as mensagens coletadas foram produzidas em domínio público, uma rede social com acesso aberto a todos os que acessaram as hashtags referidas e não revelamos identidades de membros. 


\section{RESULTADOS E DISCUSSÃO}

Nossa análise revelou nove códigos, que foram organizados em três categorias. A seguir, eles são discutidos. Para tanto, apresentamos trechos do corpus de pesquisa para ilustrar o contexto empírico descrito e as reflexões derivadas da literatura de Estudos Culturais e CCT sobre identidade cultural e identidades de consumo, respectivamente, devido ao caráter semiindutivo da pesquisa.

\section{Nacionalismo brasileiro no consumo da NFL}

Como primeira categoria, identificamos como os fãs brasileiros da NFL estabelecem associações entre seu país e a liga como uma forma de se valorizarem como audiência. Em uma perspectiva da pesquisa do consumidor, uma identidade nacional é guiada pelo reconhecimento de que marcas, bens ou serviços são expoentes de uma nação com a qual os consumidores se identificam (KEILLOR e HULT, 1999; ZEUGNER-ROTH, ZABKAR e DIAMANTOPOULOS, 2015). No contexto das identidades culturais, Hall (2014) aponta que nacionalismo é a noção compartilhada de indivíduos e grupos que reconhecem e estabelecem características em comum, levando à ideia de pertencer a uma nação (HALL, 2014).

Um primeiro código nesta categoria revela a identificação dos fãs brasileiros da NFL com Cairo Santos, o único jogador brasileiro da liga. Sua participação na NFL desperta grande repercussão, fazendo dele uma figura popular no país. Tweets coletados em diferentes jogos com o Cairo Santos na temporada 2016-2017 demonstram como os fãs brasileiros se sentem representados como nação por terem um jogador de sua terra natal na NFL. Eles escrevem sobre o jogador com carinho e intimidade, chamando-o de "Cairão da Massa", apelido que exalta sua popularidade entre os aficionados brasileiros. Muitos tweets manifestam que ele representa o país na NFL e destacam que todo o país fica ansioso para vê-lo em ação nos jogos. Essa comoção o levou a ser nomeado embaixador da NFL no Brasil desde 2016. Um bom exemplo disso é um tweet publicado em 7 de setembro de 2017, durante o jogo de abertura da temporada, quando um fã da liga escreveu “Cairão da Massa, herói do povo brasileiro \#ChiefsKingdom \#NFLnaESPN".

Os fãs brasileiros torcem pelo jogador como se fosse um time esportivo que representa o país internacionalmente. Esse sentimento é transferido para o time que ele joga, mas apenas por fidelidade ao jogador. Isso ficou evidente quando ele foi demitido do Kansas City Chiefs, seu primeiro time na NFL, depois de uma lesão sofrida na terceira semana da temporada 2017-2018. Anteriormente apoiando a equipe, os fãs brasileiros da NFL ficaram com raiva dos Chiefs. Os tweets publicados na ocasião provocavam o antigo time do atleta, afirmando que eles haviam mexido com as pessoas erradas, dispensando o único brasileiro da liga. Inúmeros fãs brasileiros começaram a registrar que, a partir daquele momento, eles torceriam contra o Kansas City Chiefs. Várias foram as mensagens postadas desejando má sorte ao time e ao jogador que substituiu Cairo Santos.

Para quem disse que a praga brasileira não pega, isso é pelo Chiefs terem demitido Cairão da Massa. MEU TITANS É GIGANTE [6 de janeiro de 2018].

\#NFLnaESPN @everaldomarques e @pauloantunes isso foi muita Zica do Brasil em cima do Butker... Kkkk... Em honra ao Cairão da massa! [6 de janeiro de 2018].

Nas temporadas seguintes, Cairo Santos sofreu com lesões que o levaram a trocar de time (e.g., Chicago Bears, Los Angeles Rams) ou até ficar sem contrato. Durante um jogo de playoff, em um período em que ele estava desempregado, um fã lembrou dele ao reclamar após a jogada ruim de um jogador da mesma posição que o brasileiro: “Onde está Cairão da Massa na NFL? Onde? \#NFLnaESPN \#MINvsGB" [16 de setembro de 2018].

Mais tarde, quando ele foi contratado pelo Los Angeles Rams para substituir um jogador lesionado por apenas algumas semanas, um fã comemorou: “Agora o Los Angeles Rams é meu time desde pequeninho. Vai Cairo Santos!" [2 de outubro de 2018]. Duas semanas depois, quando o jogador brasileiro foi demitido, outro fã protestou: "\#NFLnaESPN Cairão da massa dispensado dos RAMS? O cara arrebenta contra Seattle e Broncos e é dispensado? Como é isso?" [17 de outubro de 2018].

Em outra evidência de nacionalismo, o próximo código destaca o fato de o principal jogador da liga ser casado com uma celebridade brasileira. A supermodelo internacional brasileira Gisele Bündchen é esposa de Tom Brady, jogador do New England Patriots e um dos maiores da história da NFL. Devido a esse relacionamento, os fãs brasileiros da NFL o apelidaram de "Giselo" - uma forma masculina para o nome de sua esposa. Essa brincadeira espirituosa revela um vínculo de intimidade construído 
pelos torcedores com o atleta a partir de sua relação conjugal com uma brasileira. Tweets bem-humorados associam as boas performances do atleta ao seu casamento com Bündchen. Além disso, seu apelido é usado para exaltar essas performances, bem como brincar com a modelo quando a equipe de seu marido está perdendo. Em um tweet publicado em 13 de janeiro de 2018, um fã brinca: “@CurtiAntony Uma pergunta, se a Gisele Bündchen é brasileira, ela é casada com o Giselo, certo? Então o Giselo tb (sic) é brasileiro, correto?? Pq (sic) ele não joga para a seleção brasileira?? Alguém já convidou ele?? \#NFLnaESPN \#NFLPlayoffs". Em outra mensagem, depois que os Patriots perderam o jogo do título, um fã postou: "Chupa Giselo, hoje não vai acontecer \#SuperBowlnaESPN \#FlyEaglesFly" [4 de fevereiro de 2018]. Em outra situação, um fã questiona quem representa melhor o Brasil na liga: "Giselo" ou Cairo Santos: "\#NFLnaESPN começando com Patriots, do Giselo, vs Chiefs, do brasileiro Cairo Santos. Como assistiremos?" [7 de setembro de 2017].

Finalmente, o terceiro código revela a reinvindicação de fãs brasileiros de merecerem um jogo da NFL sediado no Brasil. Eles usam o fato do Brasil ser o segundo maior público mundial da liga fora dos EUA para exigir a atenção da NFL. Inúmeras mensagens ao longo das transmissões ilustram isso. Uma mensagem postada durante o jogo entre Oakland Raiders e Houston Texans, disputada na Cidade do México em 21 de novembro de 2016, exalta: "Podemos ver a felicidade dos fãs mexicanos neste \#MNF. Espero que um dia possamos ver esse sentimento aqui no Brasil \#TudoPelaNFL". A mensagem evoca que os brasileiros são um povo tão alegre e apaixonado pela NFL quanto os mexicanos. Por outro lado, apoiam o clamor dos fãs ao seguirem a partida entre Cincinnati Bengals e Washington Redskins em Londres em 30 de outubro de 2016 como na mensagem: "A NFL atravessa o oceano $\mathrm{p}$ (sic) ir jogar em Londres, terra gelada e torcida parada. Pq ñ (sic) descem p o Brasil? Aí vão ver barulho! \#TudoPelaNFL". Por fim, o perfil oficial da ESPN brasileira no Twitter (@mundoespn) também pediu um jogo no país: "Também queremos um jogo aqui no Brasil, viu dona @NFL @NFLBrasil!! A gente merece e faz \#TudoPelaNFL" [21 de novembro de 2016].

\section{Exaltação à localidade na fruição da NFL}

A segunda categoria indica como diferentes localidades brasileiras, especialmente as menos visíveis e mais distantes dos principais centros urbanos, são destacadas e valorizadas pelo público brasileiro durante a transmissão dos jogos. Pesquisas de consumido identificam que consumidores trabalham em identidades espacialmente localizadas (CHERNEV, HAMILTON e GAL, 2011; LUEDICKE, THOMPSON e GIESLER, 2010). Hall (2014), por sua vez, alega que uma das formas pelas quais a identidade cultural se manifesta é através do local de nascimento, pois ele define crenças e valores particulares, além de atuar como ponto de resistência ao processo de homogeneização da globalização.

Um código dessa categoria indica uma exaltação dos times locais de futebol americano. Os fãs brasileiros apresentam à comunidade on-line os times de futebol americano de suas cidades ou estados, nos quais jogam ou torcem. Os espectadores geralmente destacam os nomes das equipes, pois majoritariamente estes são formados pelo nome da cidade de origem associado a uma característica local, assim como acontece na NFL, como forma de valorizar as localidades. Inúmeros são os exemplos nos tweets. Em uma mensagem, um fã declarou ser fã do Maceió Marechais: "Hj (sic) é dia de Thursday Night Football, e sábado é dia de Liga Nacional, \#MaceióMarechais rumo a mais uma vitória! \#GoMarechais \#TudoPelaNFL" [15 de setembro de 2016]. O nome da equipe faz alusão aos dois primeiros presidentes do Brasil. Ambos tinham a patente mais alta do exército. Um deles nasceu na cidade de Maceió e o outro em outra cidade em Alagoas, estado de que Maceió é a capital. Em outra mensagem, um espectador pede à equipe da ESPN para dar um abraço aos fãs do Goiânia Rednecks: “\#TudoPelaNFL Mandem um abraço para a torcida do Goiânia Rednecks!!! Vamos que vamos vencer a Liga Nacional!" [2 de outubro de 2016]. A equipe foi nomeada em referência ao Velho Oeste dos EUA, devido ao fato de a cidade de Goiânia estar localizada na região Centro-Oeste do Brasil.

Outro tipo de exaltação destaca os locais sintonizados na NFL. Os fãs usam as mídias sociais para representar de suas localidades tanto para a equipe da ESPN e quanto para outros fãs da liga. Postadas de todas as partes o país, as mensagens fazem questão de registrar de quais cidades ou estados os fãs estão assistindo aos jogos. Esses tweets incluem as regiões citadas no mapa da audiência nacional da liga e seus cidadãos, pedindo, principalmente, que a equipe da ESPN cumprimente os fãs de tais localidades. Tais mensagens emanam de uma profusão de locais, desde grandes centros urbanos a cidades do interior de regiões menos conhecidas do país. Um tweet publicado em 13 de novembro de 2017 ilustra esse aspecto: "Chiapetta - RS com certeza é a menor cidade ligada na \#NFLNAESPN com 4044 habitantes segundo o último censo.". Outro não só exalta a cidade, mas também faz alusão ao time de futebol local: "Domingando na cidade do doce. Nerópolis, GO. Amigos do Universo RedNecks. \#NFLnaESPN". 
O último código desta categoria destaca o impacto dos fusos horários brasileiros na fruição do consumo da NFL. Durante parte da temporada da NFL, os horários dos jogos são afetados pelo final do horário de verão nos EUA e seu início no Brasil. No meio da temporada regular, a rotina dos telespectadores brasileiros é alterada, principalmente em relação aos jogos noturnos. Os horários de transmissão são atrasados em duas horas para as principais cidades do país, localizadas no eixo sul e sudeste do país. Essa mudança faz com que os espectadores do Nordeste e do Norte assistam aos jogos mais cedo, o que é destacado como uma grande vantagem. Em um tweet, um fã destaca este ponto: "A vantagem de morar no Acre é aqui ainda são 23:00 (só essa vantagem mesmo) kk \#tudopelaNFL" [7 de novembro de 2016]. Em resposta à mensagem, outro fã, que mora na região sudoeste, traz uma boa ilustração que mostra o mapa do fuso horário brasileiro, destacando os privilégios da região norte. Brincando, o remetente diz: "Prá que fazer isso? Abraço prá o povo do Acre! Sempre assíduos no \#TudoPelaNFL" [7 de novembro de 2016], revelando inveja de seus moradores, pois o estado não é afetado pela mudança de horário por estar no mesmo fuso horário da costa leste dos EUA.

\section{Minorias sociais na audiência Brasileira da NFL}

A última categoria revela que, apesar do público de futebol americano estar associado a homens heterossexuais, o público brasileiro da NFL conta com mulheres e homossexuais. Hall (2017) entende que as identidades de gênero não são concepções naturais, mas construções sociais constituídas por forças políticas, econômicas e socioculturais ao longo do tempo e demarcadas espacialmente. A apropriação e ressignificação das práticas de consumo podem contribuir para a identidade feminina, na medida em que propiciam resistência a estruturas de significados sociais dominantes (FUNG, 2002; MANSVELT, BREHENY e STEPHENS, 2015). O mesmo pode ser dito em relação à identidade gay, uma vez que práticas de consumo são usadas para naturalizar e legitimar esse modo de vida (KATES, 2002). No entanto, essas práticas realizadas por um público socialmente estigmatizado tendem a ser repudiadas por parte dos consumidores (MANSVELT, BREHENY e STEPHENS, 2015).

O sétimo código demonstra o ativismo feminino no fandom brasileiro da NFL. As mulheres mostram sua participação na comunidade de fãs e divulgam perfis especializados da NFL gerenciados exclusivamente pelo público feminino. A equipe de transmissão da ESPN geralmente exalta a participação feminina nas hashtags e, no início da temporada 2016-2017, informou que cerca de $45 \%$ da audiência da NFL no país é composta pelo público feminino. Após este anúncio, várias mensagens destacaram que assistir à NFL no Brasil é algo habitual para ambos os sexos. Em 8 de setembro de 2016, uma fã repetiu os dados divulgados durante a transmissão do tweet: " $45 \%$ da audiência só mulheres, estamos cada vez mais ganhando o mundo \#TudoPelaNFL".

Um dia emblemático para o público feminino foi em 9 de outubro de 2016, quando a ESPN exibiu um documentário produzido pela NFL antes do Sunday Night Football, o jogo semanal de maior audiência da liga. O filme de trinta minutos mostra como o futebol americano, e a NFL em particular, tem se esforçado para alcançar o público feminino. Entre os vários tweets publicados naquela noite, o crescimento das mulheres na audiência esportiva é comemorado como uma vitória sobre o preconceito, enfatizando que o mundo não pertence aos homens. Um tweet pode exemplificar esse sentido: "Issso aeeeeee mulheres crescendo no futebol americano! Vencendo o preconceito, o mundo ñ (sic) é dos homens. \#TudoPelaNFL".

Em outro evento emblemático, o público feminino ecoou veementemente duas ocorrências na transmissão do jogo entre o Los Angeles Chargers e o Denver Broncos em 11 de setembro de 2017. Pela primeira vez, uma mulher narrou um jogo da NFL na TV dos EUA. Simultaneamente, Paula Ivoglo, membro do perfil da NFL @nfldebolsa, gerenciado exclusivamente por mulheres, foi a primeira comentarista a participar de uma transmissão brasileira da NFL, posteriormente integrada permanentemente à equipe da ESPN. A comoção sobre esse feito resultou em um grande número de tweets sobre os assuntos naquela noite, com as fãs enfatizando como se sentiam representadas.

Avisa lá o misógino que na transmissão da ESPN tem uma mulher na cabine \#NFLnaESPN [11 de setembro de 2017].

tem uma mulher narrando o jogo dos EUA e outra comentando na ESPN brasileira? ESSE MOMENTO É MEU!!!! \#NFLnaESPN [11 de setembro de 2017].

Pois se conformem: lugar de mulher é onde ela quiser. Vai ter mulher narrando, jogando, comentando, VAI TÊ MULHÉ (sic) PRA TODO LADO \#NFLnaESPN [13 de setembro de 2017]. 
Em outro tweet, um fã do sexo masculino apoia esta tendência: "Muito maneiro ouvir uma voz feminina comentando FA. Mais mulheres na NFL \#NFLnaESPN" [11 de setembro de 2017].

O código seguinte trata da representação gay entre o público brasileiro da NFL. Esse público surgiu junto com a enorme repercussão do show de Lady Gaga no intervalo do Super Bowl LI, em 5 de fevereiro de 2017. A artista é um ícone LGBT e sua performance acabou atraindo o público. Naquela noite, os fãs de Gaga fizeram questão de registrar sua presença como parte da audiência sintonizada na transmissão. Além disso, um grande número de telespectadores relatou que o show havia sido sua porta de entrada para a liga. Os tweets elogiaram a presença do público gay na audiência da liga e muitas mensagens apontaram que a exibição de um ícone LGBT traz representatividade em um esporte em que a etnia, idade e corpo dos atletas já são diversas.

Duas mensagens servem como bons exemplos:

E eu que vim pra ver o show de Lady Gaga e agora tô preocupado com o resultado do jogo? \#Super BowlnaESPN [5 de fevereiro de 2017].

Hoje é o dia que a espn vai ter a melhor audiencia: as gay (sic) e os little monster tutti, aproveitem esse dia especial \#SuperBowlnaESPN. [5 de fevereiro de 2017].

Num tom contrário, o último código evidencia como a homofobia é perpetuada por parte do público brasileiro da NFL. Como reação às mensagens do público gay, parte da audiência heterossexual masculina criticou a escolha de Lady Gaga para o show do intervalo, bem como a presença de gays no fandom. Muitos tweets desdenharam e ridicularizaram o público LGBT sintonizado na transmissão e argumentaram que a virilidade do futebol americano não combina com eles nem com a performance do artista. Eles ainda fizeram "piadas" que se homens ou seus filhos estivessem gostando do show, essa seria uma maneira de indicar um comportamento gay.

Tweets publicados na hora do show ilustram este código:

Futebol americano um esporte de macho Alpha que exala testosterona, que tem briga e sangue, aí colocam Lady Gaga pra tocar. \#SuperBowInaESPN [5 de fevereiro de 2017].

Se seu filho decidiu assistir \#SuperBowlnaESPN pela primeira vez e está balançando os pés na música da Lady Gaga, eu tenho uma péssima notícia pra você [5 de fevereiro de 2017].

Outros tweets nesse tom também foram vistos. Uma mensagem postada em 26 de outubro de 2017 ilustra bem essa situação ao criticar a qualidade dos comentários de Paula Ivogllo, dizendo que "\#NFLnaESPN ESPN vai ter cota pra gay, nordestino, índio, negro, chinês e boliviano também?".

\section{CONSIDERAÇÕES FINAIS}

Voltando ao objetivo da pesquisa, podemos atestar que os fãs brasileiros da NFL constituem identidades culturais em suas interações nas mídias sociais durante as transmissões dos jogos da liga, negociando a produção de significados a partir dos conteúdos recepcionados. Isso é feito não apenas em relação ao conteúdo específico dos jogos, mas também ao conhecimento e contexto que os fãs têm sobre a liga e até sobre questões que extrapolam o jogo.

A NFL é percebida como intrínseca à cultura dos EUA e à masculinidade, devido à sua virilidade atlética. Esses aspectos se tornaram a base de como a liga foi ressignificada pelos torcedores brasileiros na formação de suas identidades culturais de consumo. Por um lado, nossas descobertas revelam identidades fortemente relacionadas à noção de lugar, no sentido de nacionalismo ou na valorização de localidades específicas. Por outro lado, mostram como identidades diferentes da héteronormativa são apresentadas.

A identidade nacional dos torcedores brasileiros é exercida exaltando aspectos de sua terra natal em relação à NFL. Seja por meio de um compatriota, da relação conjugal da maior estrela do esporte ou do desejo de sediar jogos da NFL, os fãs brasileiros proclamam o quão relevante o país é para na fruição da liga. Essa articulação projeta uma imagem idealizada da nação. Especificamente, revela o papel relevante de uma característica do consumidor em seu relacionamento com a marca consumida, fazendo com que um esporte tipicamente americano seja apreciado com base em uma negociação multiculturalista. 
A valorização de compatriotas (códigos 1 e 2) e o desejo de participação do país na liga (código 3) mostram, respectivamente, uma herança nacional do consumidor e um etnocentrismo do consumo (KEILLOR e HULT, 1999). Ambos os aspectos são consistentes com o nacionalismo definido por Hall (2014): uma identidade cultural capaz de abranger características e desejos compartilhados por indivíduos ou grupos que estabelecem o sentido de pertencer a uma nação.

Enquanto a primeira identidade cultural identificada se refere a um senso coletivo de pertencer a uma nação, a segunda destaca o pertencimento a uma determinada localidade. Ao exaltar os lugares onde eles moram ou nasceram, os fãs demonstram a importância dos locais em um país continental. Valorizar certas regiões no fandom brasileiro da NFL é um comportamento emblemático de demarcação das diferenças sociais e econômicas que geralmente reduzem o país a seus polos mais desenvolvidos. Assim, apesar das interações ocorrerem em torno de um produto cultural estrangeiro, identificamos tensões inerentes às diferenças existentes no próprio país. Os três códigos desta categoria revelam como peculiaridades (i.e., aspectos culturais, exaltação local ou fuso horário) de um local afetam a experiência do consumo (CHERNEV, HAMILTON e GAL, 2011; LUEDICKE, THOMPSON e GIESLER, 2010). Tal conceito ressoa que uma identidade cultural manifesta o local onde se vive ou nasceu, bem como crenças e valores que resistem à globalização (HALL, 2014).

Por fim, o consumo da NFL no Brasil fornece formas de representatividade para duas identidades que geralmente não estão associadas ao consumo de esportes: feminino e gay. No entanto, embora as mulheres pareçam estarem engajadas à fanidade do esporte por meio da demarcação de identidade, o incidente crítico que atraiu o público gay pode ou não ter ramificações em seu envolvimento com o esporte. Esses posicionamentos parecem ser influenciados pelo comportamento masculino em relação a eles. Enquanto as mulheres parecem ter uma boa aceitação entre o público masculino, o mesmo não ocorre com os gays, que são assediados, em um comportamento preconceituoso que dá indícios de querer preservar a identidade héteromasculina fortemente associada ao esporte. Tanto os casos de mulheres que expressam relevância social e notoriedade por meio de práticas de consumo (FUNG, 2002; MANSVELT, BREHENY e STEPHENS, 2015) quanto os gays buscando inclusão em nichos de consumidores tipicamente heterossexuais (KATES, 2002), mesmo quando estigmatizados (MANSVELT, BREHENY e STEPHENS, 2015), revelam identidades em um processo de construção social. Essas dinâmicas revelas tensões e conformidades, destacando a construção social de gênero e a apropriação do produto como elemento simbólico desse processo. É precisamente nessa questão que Hall (2017) define como as identidades culturais são constituídas por forças políticas, econômicas e socioculturais.

A presente pesquisa traz a reflexão de como a interatividade nas mídias sociais possibilita não apenas a expressão, mas também a formulação, legitimação e manutenção de identidades culturais estabelecidas em práticas de consumo. Ao fazer isso tendo como referência um esporte de mídia, aponta como o entretenimento global desempenha um papel importante na configuração das identidades contemporâneas. A abordagem teórica interdisciplinar e a assunção da NFL como produto de mídia e de seus consumidores como fãs amplia o escopo da pesquisa da CCT entre culturas e ideologias de mercado e a formação de identidades (ARNOULD e THOMPSON, 2007).

A escolha feita para o desenho da pesquisa pode ser caracterizada simultaneamente como um limite e uma limitação, uma vez que apenas a parte da audiência da NFL brasileira envolvida nas mídias sociais foi observada. Como limitação, exclui a parte do público que não expressa suas opiniões nas mídias sociais. Como limite, é uma escolha incidental, alinhada ao problema de pesquisa, que enfoca os consumidores engajados na cultura participativa (JENKINS, 2008). Outra limitação diz respeito à temporalidade da coleta de dados, reduzida a duas temporadas na NFL, o que é justificado pela viabilidade do trabalho.

Por fim, deixamos como sugestão para futuras pesquisas a investigação de fãs brasileiros de outros esportes americanos, como a Major League Baseball (MLB) e a National Basketball Association (NBA), envolvidos em mídias sociais. Tais estudos podem fornecer comparações com nossos resultados. Além disso, com base nos achados apresentados, as pesquisas poderiam se concentrar na formação de identidades culturais presentes na fruição de produtos de mídia global, bem como na formação de identidades relacionadas a minorias sociais no consumo da cultura pop.

\section{AGRADECIMENTOS}

Ao Conselho Nacional de Desenvolvimento Científico e Tecnológico (CNPq) que fomentou a pesquisa.

A Coordenação de Aperfeiçoamento de Pessoal de Nível Superior (CAPES) que apoia o programa de pós-graduação ao qual os pesquisadores são filiados. 


\section{REFERÊNCIAS}

ANDERSON, B. Imagined Communities: reflections on the origin and spread of nationalism. London: Verso. 1987.

APPADURAI, A. Modernity at Large: cultural dimensions of globalization. Minneapolis: University of Minnesota Press, 1996.

ARNOULD, E. J.; THOMPSON, C. J. Consumer culture theory (CCT): twenty years of research. Journal of Consumer Research, v. 31, n. 4, p. 868-882, 2005.

ARNOULD, E. J.; THOMPSON, C. J. Consumer Culture Theory (and we really mean theoretics): dilemmas and opportunities posed by an academic branding strategy. In: BELK, R. W.; SHERRY, J. F. (Eds.). Research in Consumer Behavior: consumer culture theory. Oxford: Elsevier, 2007. (Research in Consumer Behavior, v. 11). p. 3-22

ARNOULD, E. J.; THOMPSON, C. J. Introduction: Consumer Culture Theory: ten years gone (and beyond). In: THYROFF, A. E.; MURRAY, J. B.; BELK, R. W. B. (Eds.) Consumer Culture Theory. Bingley: Emerald Group Publishing Limited, 2015. (Research in Consumer Behavior, v. 17). p. 1-21.

ARVIDSSON, A.; CALIANDRO, A. Brand Public. Journal of Consumer Research, v. 42, n. 5, p. 727-748, 2015.

BARTIKOWSKI, B.; WALSH, G. Attitude toward cultural diversity: A test of identity-related antecedents and purchasing consequences. Journal of Business Research, v. 68, n. 3, p. 526-533, 2015.

BARTL, M.; KANNAN, V. K.; STOCKINGER, H. A Review and Analysis of Literature on Netnography Research. International Journal of Technology Marketing, v. 11, n. 2, p. 165-196, 2016.

BAUMANN, G; GINGRICH, A (Ed.). Grammars of identity/alterity: a structural approach. New York: Berghahn Books, 2005.

BEGNINI, S. et al. Capitalismo consciente: uma análise netnográfica em grupos da rede social LinkedIn. Cadernos EBAPE.BR, Rio de Janeiro, v. 17, n. 2, p. 277-293, 2019.

BELK, R. Digital consumption and the extended self. Journal of Marketing Management, v. 30, n. 11/12, p. 1101-1118, 2014.

BELK, R.; CASOTTI, L. M. Pesquisa Etnográfica em Marketing: Passado, Presente e Futuros Possíveis. REMark - Revista Brasileira de Marketing, v. 13, n. 6, p. 1-17, 2014.

BESSI, V. G. et al. As Tecnologias de Informação e Comunicação e sua Influência na Vivência Espaço-Temporal de Trabalhadores Bancários. Cadernos EBAPE.BR, Rio de Janeiro, v. 13, n. 4, p. 776-794, 2015.

BHATTACHARJEE, A.; BERGER, J.; MENON, G. When Identity Marketing Backfires: Consumer Agency in Identity Expression. Journal of Consumer Research, v. 41, n. 4, p. 294-310, 2014.

CASTELLS, M. O Poder da Identidade. São Paulo: Paz e Terra, 1999. (A era da informação: economia, sociedade e cultura, v. 2).

CASTELLS, M. The Rise of the Network Society. The Information age: economy, society and culture (2. ed.). Oxford: Wiley Blackwell, 2011.

CHERNEV, A.; HAMILTON, R.; GAL, D. Competing for Consumer Identity: Limits to Self-Expression and the Perils of Lifestyle Branding. Journal of Marketing, v. 75, n. 3, p. 66-82, 2011.
COSTA, F. Z. N.; LEÃO, A. L. M. S. A vida organizada dos fãs de Harry Potter. O\&S, v. 25, n. 84, p. 122-154, 2018.

COVA, B.; COVA, V. On the road to prosumption: marketing discourse and the development of consumer competencies. Consumption Markets \& Culture, v. 15, n. 2, p. 149-168, 2012.

COVA, B.; COVA, V. CCT applied research and the limits of consumers heroicisation. Journal of Marketing Management, v. 30, n. 11-12, p. 1086-1100, 2014.

COVA, B.; PACE, S. Brand community of convenience products: new forms of customer empowerment - the case of "my Nutella The Community". European Journal of Marketing, v. 40, n. 9-10, p. 1087-1105, 2006.

COVA, B.; PACE, S.; SKÅLÉN, P. Brand volunteering: Value co-creation with unpaid consumers. Marketing Theory, v. 15, n. 4, p. 465-485, 2015.

DUFFETT, M. Understanding fandom: an introduction to the study of media fan culture. London: Bloomsbury Publishing, 2013.

DU GAY, P. Production of culture/cultures of production. London: Sage, 1997.

ESPN BRASIL. Brasil é 20 país com mais fãs de NFL fora dos EUA, diz pesquisa. ESPN, São Paulo, 04 fev. 2015. Disponível em: <http:// espn.uol.com.br/noticia/481491_brasil-e-2-pais-com-mais-fas-denfl-fora-dos-eua-diz-pesquisa>. Acesso em: 28 nov. 2018.

ESPN BRASIL. ESPN quebra recorde histórico com transmissão exclusiva do Super Bowl na TV por assinatura. ESPN, São Paulo, 07 jul. 2017. Disponível: <http://espn.uol.com.br/noticia/669285_espn-quebrarecorde-historico-com-transmissao-exclusiva-do-super-bowl-na-tvpor-assinatura>. Acesso em: 28 nov. 2018.

FILLIS, I.; MACKAY, C. Moving beyond fan typologies: The impact of social integration on team loyalty in football. Journal of Marketing Management 30, n. 3-4, p. 334-363, 2014.

FIRMINO, A. Conheça a história das transmissões do Super Bowl no Brasil. A Tribuna, Santos, 04 fev. 2018. Disponível em: <https:// www.atribuna.com.br/2.713/conheça-a-história-das-transmissõesdo-super-bowl-no-brasil-1.43517> Acesso em: 05 ago. 2018.

FRANCISCHINI, G. Detentora dos direitos da NFL no Brasil, ESPN transmitirá mais de 140 partidas em nova temporada da Liga. ESPN, São Paulo, 05 set. 2018. Disponível em: <https://espnpressroom. com/brazil/press-releases/2018/09/detentora-dos-direitos-da-nfl-nobrasil-espn-transmitira-mais-de-140-partidas-em-nova-temporadada-liga/> Acesso em: 05 ago. 2018

FRANCO, S. M.; LEÃO, A. L. M. As "marcas" de uma nova fronteira vinícola: identidade cultural das marcas de vinhos do Vale do São Francisco. RECADM, v. 13, n. 3, p. 393-413, 2014.

FUNG, A. Women's Magazines: Construction of Identities and Cultural Consumption in Hong Kong. Consumption Markets \& Culture, v. 5, n. 4, p. 321-336, 2002.

GUSCHWAN, M. Fandom, brandom and the limits of participatory culture. Journal of Consumer Culture, v. 12, n. 1, p. 19-40, 2012.

HALL, S. Quem precisa de identidade? In SILVA, T. T. (Ed.). Identidade e diferença: a perspectiva dos estudos culturais. Petrópolis: Vozes, 2012. 
HALL, S. The work of representation. In: HALL, S.; NIXON, S. (Eds.), Representation: Cultural representation and cultural signifying practices (2. ed.). Thousand Oaks: Sage, 2013.

HALL, S. A identidade cultural na pós-modernidade. (12. ed.). Rio de Janeiro: DP\&A, 2014.

HALL, S. The whites of their eyes: racist ideologies and the media. In: DINES, G.; HUME, J. M. (Eds.). Gender, race, and class in media: a critical reader. (5. ed.). Thousand Oaks: Sage, 2017.

HAMILTON, K.; ALEXANDER, M. Spatial, temporal and social dimensions of a "destination-in-motion." European Journal of Marketing, v. 51, n. 11/12, p. 2101-2117, 2017

HENRIQUES, F. M.; PEREIRA, S. J. N. Autenticidade e Consumo de Rock Clássico: uma Netnografia no Facebook. REAd - Revista Eletrônica de Administração, v. 24, n. 1, p. 1-29, 2018.

HEWER, P.; GANNON, M.; CORDINA, R. Discordant fandom and global football brands: 'Let the people sing'. Journal of Consumer Culture, v. 17, n. 3, p. 600-619, 2015.

IACONO, V. L.; SYMONDS, P.; BROWN, D. H. K. Skype as a tool for qualitative research interviews. Sociological Research Online, v. 21, n. 2, p. 1-15, 2016.

IZOGO, E. E.; JAYAWARDHENA, C. Online shopping experience in an emerging e-retailing market. Journal of Research in Interactive Marketing, v. 12, n. 2, p. 193-214, 2018.

JENKINS, H. Fans, Bloggers, and Gamers: exploring participatory culture. New York: NYU Press, 2006.

JENKINS, $\mathrm{H}$. Convergence culture: where old and new media collide. New York: New York University Press, 2008.

JENKINS, H. Textual Poachers: television fans and participatory culture. New York: Routledge, 2013.

JENKINS, H.; FORD, S.; GREEN, J. Spreadable media: creating value and meaning in a networked culture. NYU Press, New York, NY, 2013.

KATES, S. The Protean Quality of Subcultural Consumption: An Ethnographic Account of Gay Consumers. Journal of Consumer Research, v. 29, n. 3, p. 383-399, 2002.

KEILLOR, B. D.; HULT, G. T. M. A five-country study of national identity: implications for international marketing research and practice. International Marketing Review, v. 16, n. 1, p. 65-84, 1999.

KOZINETS, R. V. Netnography 2.0. In: R. W. BELK (Ed.). Handbook of qualitative research methods in marketing. Cheltenham: Edward Edgar, 2006.

KOZINETS, R.V. Netnography: doing ethnographic research online. London: Sage, 2010.

KOZINETS, R.V. Netnography: redefined. London: Sage, 2015.

LANGLOIS, G. Participatory Culture and the New Governance of Communication: The Paradox of Participatory Media. Television \& New Media, v. 14, n. 2, p. 91-105, 2013.

LANIER JR., C. D.; RADIER, C. S.; FOWLER III, A. S. Ambiguity and fandom: the (meaningless) consumption and production of popular culture. Consumer Culture Theory, v. 17, p. 275-293, 2015.
LEÃO, A. L. M. de S.; COSTA, F. Z. N. Agenciados pelo desejo: O consumo produtivo dos Potterheads. RAE-Revista de Administração de Empresas, São Paulo, v. 58, n. 1, p. 74-86, 2018.

LEÃO, A. L. M. de S.; MELLO, S. C. Significação das marcas pelos consumidores em suas interações sociais: recurso simbólico de expressões de identidade cultural. REMark - Revista Brasileira de Marketing, v. 11, n. 1, p. 47-74, 2012.

LEÃO, A. L. M. de S.; MELLO, S. C.; VIEIRA, R. S. G. O papel da teoria no método de pesquisa em Administração. Revista Organizações em Contexto, v. 5, n. 10, p. 1-16, 2009.

LEÃO, A. L. M. de S.; IANATONI, T.; CAVALCANTI, R. T. Identidades Culturais de Consumidores da Pitú em sua Comunidade de Marca: Uma Netnografia da Comunicação. Revista de Gestão Organizacional, v. 8 , n. 2 , p. $60-81,2015$

LÉVY, P. Cibercultura. São Paulo: Editora 34, 1999.

LINCOLN, Y.; LYNHAM, S.; GUBA, E. Paradigmatic controversies, contradictions, and emerging confluences, revisited. In N. K. DENZIN; Y. S. LINCOLN (Eds.). SAGE handbook of qualitative research. (4. ed.). Thousand Oaks: Sage, 2011. p. 97-128.

LUEDICKE, M. K.; THOMPSON, C. J.; GIESLER, M. Consumer Identity Work as Moral Protagonism: How Myth and Ideology Animate a Brand-Mediated Moral Conflict. Journal of Consumer Research, v. 36, n. 6, p. 1016-1032, 2010.

MAGRI, D. Muito além do Super Bowl: futebol americano cresce em audiência e praticantes no Brasil. El País, São Paulo, 04 fev. 2018. Disponível em: <https://brasil.elpais.com/brasil/2018/02/01/ deportes/1517507665_087170.html>. Acesso em: 28 nov. 2018.

MANSVELT, J.; BREHENY, M.; STEPHENS, C. Still being 'Mother'? Consumption and identity practices for women in later life. Journal of Consumer Culture, v. 17, n. 2, p. 340-358, 2015.

MIGUELES, C. P.; ZANINI, M. T. F. A natureza volitiva da motivação e a criatividade cultural: uma investigação antropológica. Cadernos EBAPE.BR, Rio de Janeiro, v. 16, n. 3, p. 355-366, 2018.

OATES, T. P.; FURNESS, Z. (Eds.) The NFL: critical and cultural perspectives. Philadelphia: Temple University Press, 2014.

OLIVEIRA, M. A. C.; LEÃO, A. L. M. de S. Sendo aos olhos do outro: o papel da alteridade na construção da identidade metrossexual. Revista de Administração - RAUSP, São Paulo, v. 47, n. 2, p. 264-274, 2012.

ORIARD, M. Brand NFL: Making and selling America's favorite sport. University of North Carolina Press, Chapel Hill, North Carolina, NC, 2007.

OZANIAN, M. The Forbes Fab 40: The World's Most Valuable Sports Brands 2017. Forbes, New York, 04 out. 2017. Disponível em: <https:// www.forbes.com/sites/mikeozanian/2017/10/24/the-forbes-fab40-the-worlds-most-valuable-sports-brands-2017/\#628ecc693b84>. Acesso em: 28 nov. 2018.

RITZER, G. Automating prosumption: The decline of the prosumer and the rise of the prosuming machines. Journal of Consumer Culture, v. 15, n. 3, p. 407-424, 2015.

RITZER, G.; JURGENSON, N. Production, Consumption, Prosumption: The nature of capitalism in the age of the digital 'prosumer'. Journal of Consumer Culture, v. 10, n. 1, p. 13-36, 2010. 
RUDDOCK, A. Contradictions in media sport culture: The reinscription of football supporter traditions through online media. European Journal of Cultural Studies, v. 13, n. 3, p, 323-339, 2010.

SCARABOTO, D.; PEREIRA, S. J. N. Rhetorical strategies of consumer activists: reframing market offers to promote change. BAR - Brazilian Administration Review, v. 10, n. 4, p. 389-414, 2013.

SEIFERT, K. NFL dominates in U.S., but it lacks widespread appeal on international stage. ESPN, São Paulo, 30 maio 2017. Disponível em: <http://www.espn.co.uk/nfl/story/_id/19472417/nfl-dominatesfan-audience-united-states-lacks-widespread-appeal-internationalstage>. Acesso em: 28 nov. 2018.

SILVA, T. T. A produção social da identidade e da diferença. In: SILVA, T. T. (Ed.). Identidade e diferença. Petrópolis: Vozes, 2012.

THOMAS, T. C.; PRICE, L. L.; SCHAU, H. J. When differences unite: Resource dependence in heterogeneous consumption communities. Journal of Consumer Research, v. 39, n. 5, p. 1010-1033, 2013.

TILIO, R.C. Reflexões acerca do conceito de identidade. Revista Eletrônica do Instituto de Humanidades, v. 8, n. 29, p. 109-119, 2009.
VAN DIJCK, J. The Culture of Connectivity. A critical history of social media. New York: Oxford University Press, 2013.

WENNER, L. Reflections on Communication and Sport: On Reading Sport and Narrative Ethics. Communication \& Sport, v. 1, n. 1/2, p. 188-199, 2012.

WENNER, L. Connecting events to advertising: Narrative strategies and dirty logics in Super Bowl commercials In: DASHPER, K.; FLETCHER, T.; MCCULLOGH, N. (Eds). Sport Events, Society and Culture. Abingdon: Routledge, 2014.

WHANNEL, G. The paradoxical character of live television sport in the twenty-first century. Television \& New Media, v. 15, p. 769-776, 2014.

WOODWARD, K. Identidade e diferença: Uma introdução teórica e conceitual. In SILVA, T. T. (Ed.). Identidade e diferença: a perspectiva dos estudos culturais. Petrópolis: Vozes, 2012.

ZEUGNER-ROTH, K. P.; ZABKAR, V.; DIAMANTOPOULOS, A. Consumer Ethnocentrism, National Identity, and Consumer Cosmopolitanism as Drivers of Consumer Behavior: A Social Identity Theory Perspective. Journal of International Marketing, v. 23, n. 2, p. 25-54, 2015. 